\title{
Adaptação habitacional no Projeto Taboquinha, Icoaraci, Belém, Pará
}

Housing adaptation of the Taboquinha Project in Icoaraci, Belém, Pará

La adaptación de la vivienda en el Proyecto Taboquinha Icoaraci, Belém, Pará

\author{
Rosineide Pinho Trindade \\ Arquiteta e Urbanista, UFPA, Brasil \\ rosineidetrindade@gmail.com
}

Ana Klaudia de Almeida Viana Perdigão

Professora Doutora, UFPA, Brasil klaudiaufpa@gmail.com 


\section{RESUMO}

Objetiva-se discutir a problemática habitacional em Belém investigando-se o processo de adaptação habitacional em remanejamentos urbanos propostos pelo PAC no eixo "Urbanização de Assentamentos Precários" na cidade de Belém-PA. Para tanto, foi realizada uma oficina para registro de modificações realizadas nas unidades habitacionais e também foram aplicados formulários de consulta verbal e não verbal aos moradores residentes na área de reassentamento habitacional do Projeto Taboquinha, executado pela Companhia de Habitação do Estado do Pará. Os resultados apontam dificuldades no processo de adaptação habitacional causadas por conflitos espaciais que foram manifestados nas falas, nos desenhos e nas modificações realizadas pelos moradores, confrontados pela comparação entre a casa de origem produzida informalmente na área da comunidade Cubatão e a nova casa executada pela produção formal da habitação social. Estes resultados fortalecem pesquisas realizadas em outras áreas de assentamentos precários com base na premissa de que as rupturas no modo de morar amazônico pela produção formal de moradia tem gerado conflitos espaciais nos reassentamentos habitacionais, devido à mudança de padrão tipológico entre a casa de origem e casa destino das famílias reassentadas em programas habitacionais na cidade de Belém (PA).

PALAVRAS-CHAVE: Habitação Social. Adaptação habitacional. Habitação ribeirinha.

\section{ABSTRACT}

The objective of this work is to discuss the housing problem in Belém, investigating the housing adaptation process of the urban relocation proposed by the PAC on the axis "Precarious Settlements Urbanization", in the city of Belém, PA. For this purpose, a workshop was realized in order to record the changes made in the housing units, and were applied verbal and non-verbal inquiry forms to the residents in the housing resettlement of the Taboquinha Project, which was executed by the Housing Society of Pará State. The results indicate difficulties in the housing adaptation process, caused by spatial conflicts that were expressed in the statements, drawings and modifications made by the residents, which were confronted by comparing the original informally produced housing of the Cubatão community and the new houses built by the formal production of social housing. These results strengthen research in other precarious settlement areas, based on the premise that the changes in the traditional living in Amazon by the formal production house has generated spatial conflicts in housing resettlements, due to the change of standards between the original housing and houses destined to families resettled by housing programs in the city of Belém, PA.

KEY-WORDS: Social Housing. Housing adaptation. Riverside housing.

\section{RESUMEN}

El objetivo de este trabajo es discutir el problema de la vivenda en Belém, investigando el processo de la adaptación de la vivenda en los casos de reubicación urbana propuesto por el PAC en el eje de la "Urbanizacion de Asentamientos Precario" en la ciudad de Belém-PA. Para eso, se realizó una actividad para registar las modificaciones realizados en las unidades de vivenda y también se aplicaron formulários de consulta verbal y no verbales a los residentes en el área de reasentamiento de viviendas de lo Proyecto Taboquinha, a cargo de la Companhia de Habitação do Estado do Pará. Los resultados indican dificultades em el processo de adaptación de la vivenda causados por conflitos espaciales que son expressados en las declaraciones, en los dibujos y en las modificaciones realizados por los residentes, confrontado por comparación entre la casa original, producido de manera informal en el área de la comunidade Cubatão, y la nueva casa, realizado por la produción formal de viviendas de interés social. Estos resultados refuerzan la investigación en otras áreas de los asentamientos precários baseado en la premissa de que las roturas en la manera de vivir en la Amazonía por la casa de produccíon formal há generado conflitos espaciales em reasentamientos de vivenda, debido a la modificación estándar tipológico entre la casa original y la casa de destino de las famílias reassentadas por médio de programas de vivenda en la ciudad de Belém (PA).

PALAVRAS-CHAVE: La vivienda social. Adaptación de la vivienda. Vivienda de ribera. 


\section{INTRODUÇÃO}

Milhares de famílias residem em áreas de assentamentos precários no Brasil, ocupadas de maneira espontânea, apresentando algum tipo de vulnerabilidade como riscos ambientais e sendo caracterizada pela precariedade habitacional e urbana. O Programa de Aceleração do Crescimento - PAC, do governo federal (BRASIL, 2007), apresenta eixo especifico para tratar questões de áreas precárias visando a incorporação das mesmas à cidade formal.

O PAC urbanização de assentamentos precários, como é denominado o eixo, apresenta uma abordagem ampla com a proposta de solucionar os mais variados problemas detectados em áreas de assentamentos humanos marcados pela precariedade. Assentamentos que foram, em grande parte, formados a partir da autoconstrução da moradia e tratam-se de ocupações consolidadas, com condições mínimas de saneamento básico, infraestrutura e precariedade física das moradias.

A urbanização das áreas de assentamentos precários tem sido marcada pela remoção das famílias e o reassentamento das mesmas em locais providos de condições básicas urbanas. Nessas condições, o programa ressalta que os locais escolhidos para o reassentamento sejam preferencialmente locais próximos ao assentamento de modo a preservar os vínculos sociais e com o território estabelecidos pelas famílias (BRASIL, 2010).

Bonduki e Rossetto (2008) ressaltam que é a Política Nacional de Habitação - PNH, que prevê o desenvolvimento de alternativas regionais que considerem as características da população local, suas manifestações culturais, forma de organização, entre outros. Contudo, o enfoque dado pelos próprios programas federais à padronização e à produção habitacional em larga escala visando atender uma demanda quantitativa, afasta em muito, tanto a urbanização do assentamento precário quanto a provisão de moradia do quesito qualidade.

A cidade de Belém (PA) está entre as cidades brasileiras com intervenções em áreas de assentamentos precários pelo PAC. Os assentamentos originaram-se em decorrência do tipo de ocupação realizado, que sempre esteve associado ao predomínio das terras altas pelas classes de maior poder aquisitivo, restando à população menos privilegiada a ocupação das "baixadas", ou seja, terras com cota abaixo de 4,0 metros de altura e que ficam sujeitas a inundações em boa parte do ano. Porém, nem de longe esse "entrave" representou obstáculos para ocupação das áreas de baixada, já que os imigrantes eram em grande parte provenientes de comunidades ribeirinhas que circundavam a cidade, e possuíam familiaridade com a autoconstrução da moradia sobre as águas, as conhecidas palafitas amazônicas.

A formação dos assentamentos precários em torno de igarapés, permite a continuação da relação com as águas já estabelecida anteriormente por essas comunidades, situação esta que permite a conservação do cultivo da pesca artesanal, o contato com a natureza e a reprodução da casa ribeirinha que, além de oferecer muitos benefícios relacionados ao conforto térmico, ainda "carrega" um valor simbólico adquirido através das tradições culturais e espaciais locais. 
Contudo, para o mercado imobiliário e poder público, as áreas de baixada são vistas apenas do ponto de vista de obstáculos que causam entraves ao crescimento da cidade. Por isso, com discurso de integração ao espaço urbano "ordenado", já que algumas dessas áreas encontra-se no centro urbano da capital, iniciou-se a implementação de vários projetos de urbanização ao longo da história da cidade, Abelém (1989). Destaca-se, no entanto, as ações mais evidentes na atualidade para a busca de melhoria ambiental por meio da Urbanização de Assentamentos precários do PAC, que, na capital paraense, apresentam uma lógica de intervenção muito voltada para questões urbanas para provisão de infraestrutura básica e melhoria do saneamento, uma vez que o objetivo principal das intervenções demonstrou ser a integração das áreas precárias ao espaço urbano ordenado; porém, pouco efetiva em questões referentes às moradias produzidas, visto que os conflitos espaciais e problemas com a adaptação habitacional pelos moradores ainda permanecem sem solução. Esta situação põe em jogo a real qualidade de vida das famílias atendidas, uma vez que, intervir em assentamentos precários consolidados, principalmente quando incluem o remanejamento/reassentamento da população, requer atenção a todos os fatores que influenciarão o processo.

Com isso, os resultados tem sido o aparecimento de conflitos espaciais entre o morador e o espaço proposto, resultando em dificuldades no processo de apropriação e adaptação espacial, gerando, inclusive situações de venda das unidades entregues aos beneficiados e consequente formação de novas áreas ou adensamentos de áreas onde ainda existem assentamentos precários na cidade. Os conflitos espaciais revelam a importância do espaço arquitetônico que é defendido por Malard (2006) quando explica a gênese desse espaço como decorrente da espacialidade que é inerente ao ser humano, pois este realiza todas as suas atividades no espaço, sendo este um componente essencial das ações humanas, e é onde a cultura ribeirinha e seus hábitos espaciais locais não tem sido contemplados nos projetos de habitação social.

Por isso, com objetivo de discutir a problemática habitacional em Belém por meio da adaptação do morador no contexto da ocupação humana, apresentam-se os resultados coletados neste estudo como parte da pesquisa intitulada "O PAC Urbanização de Assentamentos Precários em Cidades Amazônicas: proposta metodológica para avaliação da produção e ocupação humana na política habitacional em Belém e Macapá". Os resultados apontam conflitos espaciais existentes no reassentamento de famílias, conhecido como Projeto Taboquinha que é oriundo de um assentamento precário, cujas origens estão vinculadas ao modo de habitar ribeirinho trazido e adaptado à realidade da cidade de Belém (PA).

\subsection{CARACTERIZAÇÃO DA ÁREA DE ESTUDO}

A área de estudo trata-se como, já mencionado, de um assentamento precário localizado no Distrito de Icoaraci, bairro do Cruzeiro, situado na área de expansão de Belém e distante em média $18 \mathrm{~km}$ do centro comercial da cidade. 
A comunidade passa desde 2008 por um processo de urbanização oriundo do Programa de Aceleração do Crescimento (PAC) do governo Federal no eixo "Urbanização de assentamentos Precários". A intervenção tem contrapartida Estadual, órgão executor a COHAB-PA e órgão fiscalizador a Caixa Econômica Federal. As ações previstas para a área envolvem obras integradas de regularização fundiária, serviços de infraestrutura básica (sistema de drenagem, rede de distribuição de água, sistema de esgoto sanitário, sistema viário, terraplenagem, pavimentação, arborização e preservação ambiental), erradicação das palafitas, produção de moradia para atender as famílias remanejadas e trabalho técnico social em parceria com o Movimento Nacional de Luta pela Moradia (COHAB-PA, 2011).

De acordo com os dados do levantamento socioeconômico, fornecido pela executora do projeto, este beneficiará 1.862 famílias (aproximadamente 9.310 pessoas) sendo de grande impacto por envolver uma alta quantidade de remoção, precisamente 1.014 imóveis seriam atingidos diretamente com necessidade de remanejamento (COHAB-PA, 2009, 2011). A provisão habitacional consta de: construção de 66 unidades habitacionais térreas com área de $39 \mathrm{~m}^{2}$ contendo dois quartos, banheiro, sala/cozinha; melhoria de 100 unidades habitacionais de acordo com a necessidade encontrada em cada uma; e construção de 912 unidades habitacionais tipo sobrado com área de 43,62 $\mathrm{m}^{2}$ distribuídos em sala/cozinha, banheiro e dois quartos, e ainda contém uma área de quintal.

Figura 03: Unidades propostas pela COHAB-PA para o projeto Taboquinha.
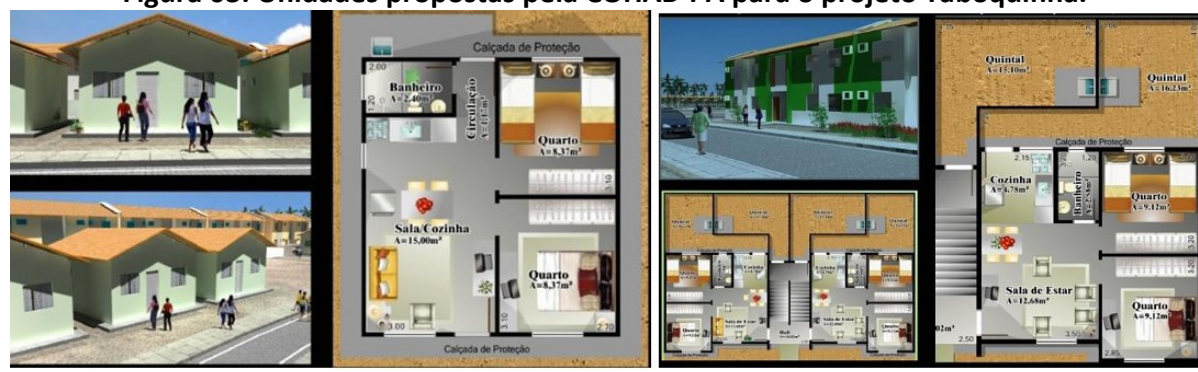

Fonte: $\mathrm{COHAB/PA}, 2010$.

Observa-se na Figura 03 que a configuração das unidades, casa e sobrado, é a mesma apresentada em outros projetos de habitação para baixa renda de outras regiões do Brasil, o que vêm tronando tais projetos impessoais e sem condições de atender às necessidades particulares das diferentes famílias, demonstrando que a política habitacional brasileira tem reduzido a questão habitacional a um problema numérico (LOGSDON; AFONSO; OLIVEIRA, 2011), em que a padronização, a replicabilidade e condições básicas de urbanidade tem sido a prioridade. As melhorias trazidas por essas intervenções concentram-se na mudança do material construtivo da moradia (que era de madeira e passa a ser em alvenaria) e melhorias relacionadas a aspectos externos à casa: infraestrutura e saneamento. Reforça-se, no entanto, 
que intervir em áreas com ocupações humanas consolidadas representa um desafio onde as várias problemáticas identificadas necessitam receber grau de atenção semelhante. Esse desafio torna-se um tanto maior quando a intervenção se utiliza do remanejamento de população, visto que essa prática envolve perdas tanto físicas quanto afetivas que necessitam ser amenizadas no reassentamento.

\section{OBJETIVOS}

Avaliar a adaptação espacial em projeto de arquitetura de habitação social destinada a remanejamentos urbanos - o caso do Projeto Taboquinha em Belém (PA), identificando as principais melhorias trazidas com a urbanização dos assentamentos precários e apontando rupturas espaciais a partir da produção formal de moradia.

\section{METODOLOGIA}

A metodologia utilizada trata-se de Pesquisa de campo com: aplicação de formulário não verbal na área da produção informal (comunidade Cubatão); Aplicação de formulário verbal de adaptação habitacional aos moradores reassentados no Projeto Taboquinha; e oficina in loco também realizada com moradores reassentados através do Projeto.

O formulário de consulta não verbal, desenvolvido por Perdigão (2005) busca respostas dos moradores da área de origem dos reassentados, a comunidade Cubatão, em Icoaraci (PA), para relacionar a subjetividade do habitar (casa da infância, casa atual e casa dos sonhos) e os elementos geométricos dos espaços habitacionais, conforme Quadro 01. Foram aplicados com moradores que estavam na iminência de remanejamento para os empreendimentos habitacionais do Projeto Taboquinha, totalizando seis famílias a serem avaliadas do ponto de vista qualitativo para identificar evidências das referências espaciais dos moradores alvo de remanejamento.

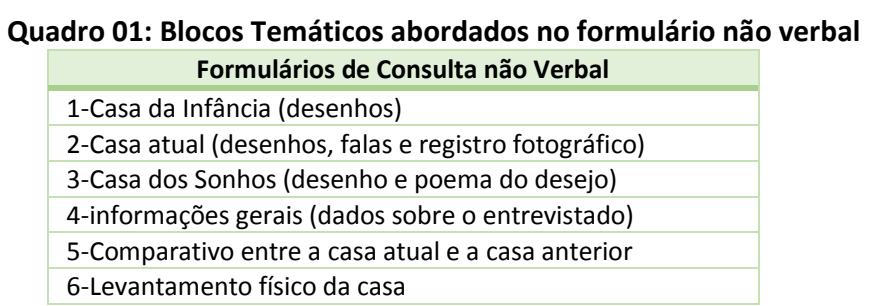

Fonte: EQUIPE DE PESQUISA. LABORATÓRIO DE ESPAÇO E DESENVOLVIMENTO HUMANO (LEDH), 2014.

O formulário verbal de adaptação habitacional foi elaborado por uma equipe de pesquisa durante o desenvolvimento do projeto "O PAC Urbanização de Assentamentos Precários em Cidades Amazônicas: proposta metodológica para avaliação da produção e ocupação humana na política habitacional em Belém e Macapá". A equipe contou com pesquisadores e bolsistas do projeto em algumas áreas de conhecimento envolvidas, sendo elas: Arquitetura e 
Urbanismo, Psicologia e Serviço Social. O formulário possui itens referentes a aspectos sociodemográficos; comparativo entre a casa atual e a anterior nos quesitos tempo de moradia, composição familiar, tipologia da casa, preferências e uso da casa; situação atual tratando de residência e áreas comuns; e avaliação e perspectiva do morador em relação à casa atual. Foram aplicados, pelos bolsistas da referida pesquisa, 137 formulários sobre adaptação habitacional na área de reassentamento (Projeto Taboquinha) no período de 13 de novembro de 2014 a 9 de janeiro de 2015, totalizando 12 visitas na área para conclusão dos mesmos. O Quadro 02 apresenta os blocos temáticos abordados no formulário.

\begin{tabular}{|l|l|}
\multicolumn{1}{|c|}{ Quadro 02: Blocos Temáticos abordados no formulário de adaptação } \\
\hline 1-Identificação da área \\
\hline 2-Sociodemográfico (características dos entrevistados) \\
\hline 3-Antes e depois do remanejamento: comparativo entre a casa atual e a anterior \\
\hline 4-Situação atual (nível de adaptação da casa atual) \\
\hline 5-Avaliação e Perspectiva (sobre a casa atual) \\
\hline
\end{tabular}

Também foi realizada na área de reassentamento (Projeto Taboquinha) uma oficina, com duração de um dia, que integra o projeto de pesquisa mencionado. A oficina promove dialogar com os moradores com material gráfico para registrar modificações desejadas e realizadas na unidade no pós reassentamento. A análise dos resultados proporciona a elaboração de quadro que revela as dificuldades no processo de adaptação dos moradores no pós reassentamento, que é observada a partir das adaptações já realizadas e as desejadas nas unidades habitacionais entregues pelo poder público.

\section{RESULTADOS}

Os resultados a seguir foram selecionados visando atender aos objetivos propostos por este estudo. Os itens retirados do formulário verbal de adaptação, têm por objetivo mostrar a insatisfação de parte dos moradores com a nova moradia, bem como que aspectos estão sendo melhor atendidos pelos programas de urbanização de assentamentos precários que trazem a produção de moradia como fator de extrema importância; os resultados apresentados do formulário não verbal e da oficina com os moradores reassentados visam mostrar os referenciais de habitação da população local, e como eles estão atrelados a cultura do habitar do ribeirinho, e ainda como estes referenciais são rompidos nas casas da produção formal e o que os moradores fazem para resgatar esses vínculos e adaptar as unidades às suas necessidades e expectativas.

\subsection{FORMULÁRIO DE ADAPTAÇÃO HABITACIONAL}

No bloco temático "situação atual da casa na produção formal" os moradores, já reassentados pelo Projeto Taboquinha, foram questionados com relação a como veem a nova 
casa. Dentro deste item, os moradores avaliaram o tamanho de cada cômodo, podendo enquadrá-los entre as alternativas "ruim" e "regular" que foram associadas na categoria "negativo", e "bom" e "ótimo" associadas na categoria "positivo", conforme Quadro 03.

Os resultados revelam conflitos com o espaço doméstico, pois dos $100 \%$ de moradores pesquisados (137), as respostas na categoria negativo se aproximam quase da metade do total de $100 \%$ em pelo menos cinco dos sete itens avaliados, sendo o caso mais crítico o "tamanho da cozinha" por ser extremamente pequena e não possuir nenhum tipo de "barreira" que a separe da sala, fato que para muitos moradores representa estranheza, já que as palafitas em sua maioria possuem essa clara separação do setor social com o de serviço.

\begin{tabular}{|c|c|c|c|}
\hline Tamanho... & Positivo & Negativo & N.S. A \\
\hline da unidade habitacional & $54 \%$ & $46 \%$ & \\
\hline da Cozinha & $32 \%$ & $68 \%$ & \\
\hline do Banheiro & $54 \%$ & $46 \%$ & \\
\hline da Sala & $65 \%$ & $35 \%$ & \\
\hline dos Dormitórios & $74 \%$ & $26 \%$ & \\
\hline da Área de serviço & $53,3 \%$ & $45,2 \%$ & $1,5 \%$ \\
\hline Disposição dos cômodos & $56 \%$ & $44 \%$ & \\
\hline
\end{tabular}

Fonte: PESQUISA DE CAMPO, 2014.

Com relação à disposição dos ambientes, os conflitos relatados frequentemente pelos moradores referem-se à localização da área de serviço dos apartamentos do segundo pavimento que é no térreo, exigindo grande mobilidade vertical durante a realização das tarefas diárias, à circulação compacta e a localização do banheiro próximo à sala, já que nas habitações ribeirinhas, predominância da origem dos moradores dessas comunidades, este se localiza ao fundo da residência ou em área externa.

No bloco temático "avaliação e perspectiva da casa atual (produção formal)" os moradores foram questionados sobre a "percepção entre a residência atual em relação à anterior" podendo escolher entre as opções "igual, melhorou, melhorou muito, piorou e outros" e ainda justificar a resposta. O Quadro 04 apresenta algumas das 67 respostas (foram aplicados um total de 137 formulários) dos moradores que para justificar as melhorias da casa atual em relação à anterior recorreram a aspectos que não estavam relacionados à espacialidade (casa, vínculo, tamanho), e sim questões ligadas ao sistema construtivo, saneamento e infraestrutura. As categorias foram atribuídas para melhor identificar que melhorias foram mais recorrentes de acordo com a fala dos moradores. 
Fonte: PESQUISA DE CAMPO, 2014. Elaboração: ROSINEIDE TRINDADE. 


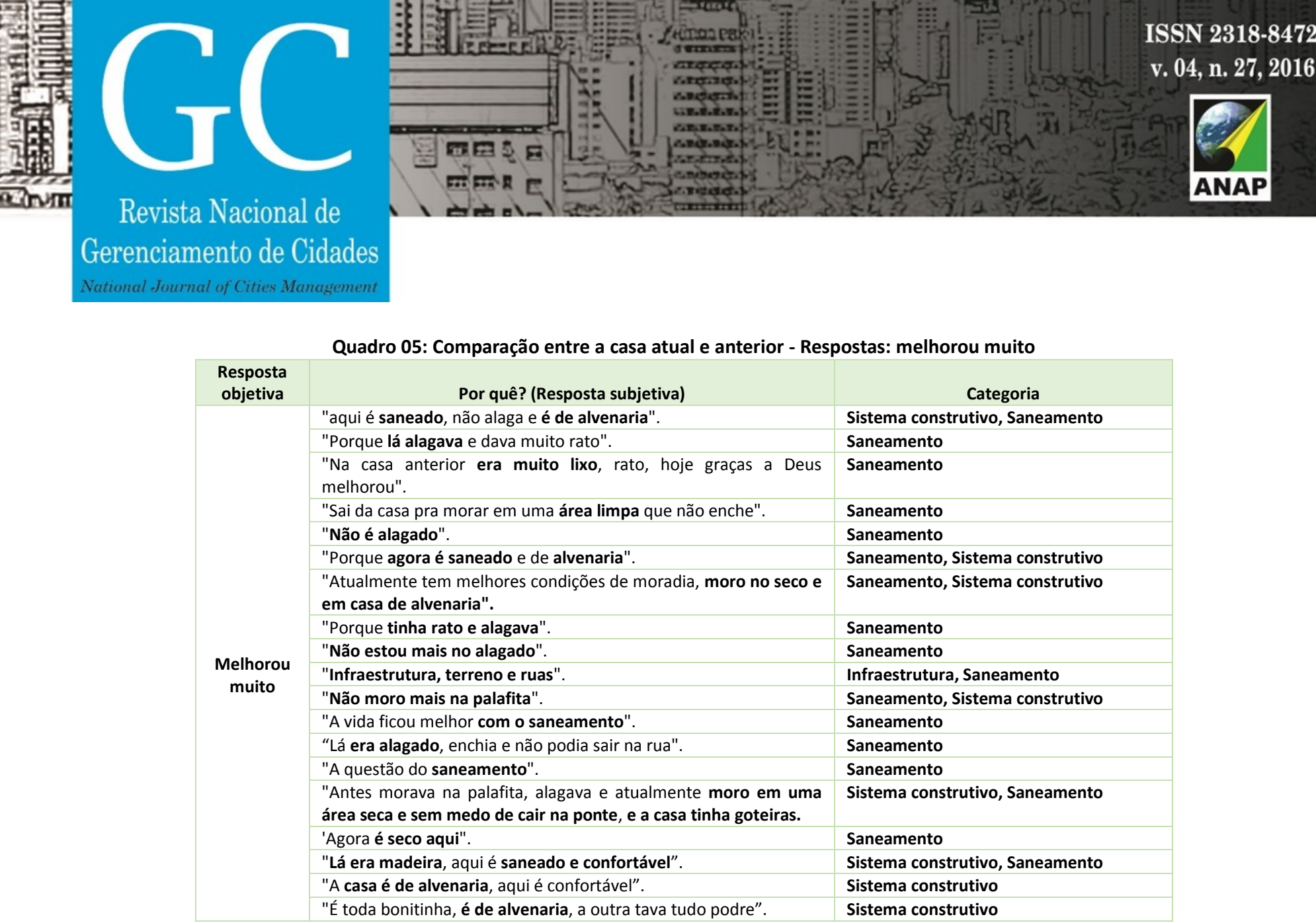

Fonte: PESQUISA DE CAMPO, 2014. Elaboração: ROSINEIDE TRINDADE.

Os resultados apontam que as intervenções destinadas a população de baixa renda na cidade de Belém, estão mais focadas na resolução de problemas voltados ao sistema construtivo e saneamento do que propriamente oferecer melhoria de vida, visto que para a resolução mais eficaz da problemática referente à moradia, o espaço projetado necessitaria considerar como fator relevante as reais necessidades do usuários finais e também suas referências espaciais, as quais permitem uma maior identificação do usuário com o novo espaço construído, aumentando as possibilidades de adaptação habitacional e fixação dos moradores no reassentamento. $\mathrm{O}$ quadro 06 apresenta algumas das respostas dos moradores que se utilizaram da espacialidade para justificar a pergunta objetiva de como percebiam a casa atual em relação à anterior. As falas mostram que alguns moradores preferem deixar claro seu descontentamento com aspectos espaciais da casa da produção formal; outros, no entanto, demonstraram tentar "se conformar" com o novo espaço, porém novamente a espacialidade se mostra como um fator importante que define a preferência ou não pela casa entregue através do projeto, assim como, a identificação com muitas características da casa da produção informal. 
Quadro 06: Algumas justificativas dos moradores relacionadas à espacialidade.

Algumas justificativas dos moradores que tinham a ver com espacialidade (casa, vínculo, tamanho)

"Não mudou muita coisa, hoje a área é saneada, mas não compensa o bem estar da antiga casa".

"Lá era melhor pra mim".

"Lá era melhor, mas agora eu moro aqui então aqui é melhor".

"Construção melhor, localização, mas lá era maior".

Melhorou no aspecto sobre a estrutura que agora não tem enchente e nem invasão de bicho, mas a casa é pequena".

"A área é seca, a casa tem conforto, mas é pequena e tem muitas rachaduras".

"Agora é menos alagado, porém não tem quintal".

"Aqui é confortável, mas lá era melhor".

"Não moro mais em área alagada, entretanto a casa é pequena e não tenho privacidade"

"Não melhorou muito, sinto saudade, lá tinha felicidade".

"Lá era de madeira, aqui é de alvenaria, mas minha casa era bem feitinha".

"Lá era de madeira, mas com relação a espaço e privacidade piorou".

"Em relação a estrutura melhorou muito, mas a casa era maior"

"A residência atual melhorou em relação a estrutura, mas eu gostava mais da casa antiga, porque era maior, ventilada, também tinha um apego muito grande por ter morado mais de $\mathbf{3 0}$ anos lá."

"A casa é muito ruim e pequena".

"A casa era maior e mais ventilada".

"Porque na minha casa anterior eu não gastava nada e era mais ventilada. Era feliz e não sabia."

"Não cabem todos os móveis".

"Aqui é pequeno, é muito quente, lá eu tinha conforto, quintal e vida feliz".

"Na minha casa anterior tinha mais espaço, conforto e segurança".

"O espaço é pequeno".

"Minha casa era muito melhor, não gostei daqui".

"Lá tinha como mudar a casa, hoje em dia não posso mudar nada"

Fonte: PESQUISA DE CAMPO, 2014. Elaboração: ROSINEIDE TRINDADE.

\subsection{FORMULÁRIO NÃO VERBAL E OFICINA COM MORADORES REASSENTADOS}

A consulta não verbal foi realizada com seis moradores que ainda residiam nas áreas de palafitas no entorno do igarapé Cubatão. Através de escrita, fala, desenhos e fotos os moradores expressaram particularidades da casa da infância, da casa atual e ainda da casa dos sonhos. O quadro 07 apresenta o desenho da casa da infância e da casa dos sonhos que são confrontados com a planta baixa modificada por um morador de um dos sobrados da área de reassentamento (Projeto taboquinha). O objetivo era apontar rupturas e permanências espaciais no processo de remanejamento e como pode se identificar a relação existente entre a realidade trazida pela produção formal de moradia e o desejo (casa dos sonhos). 


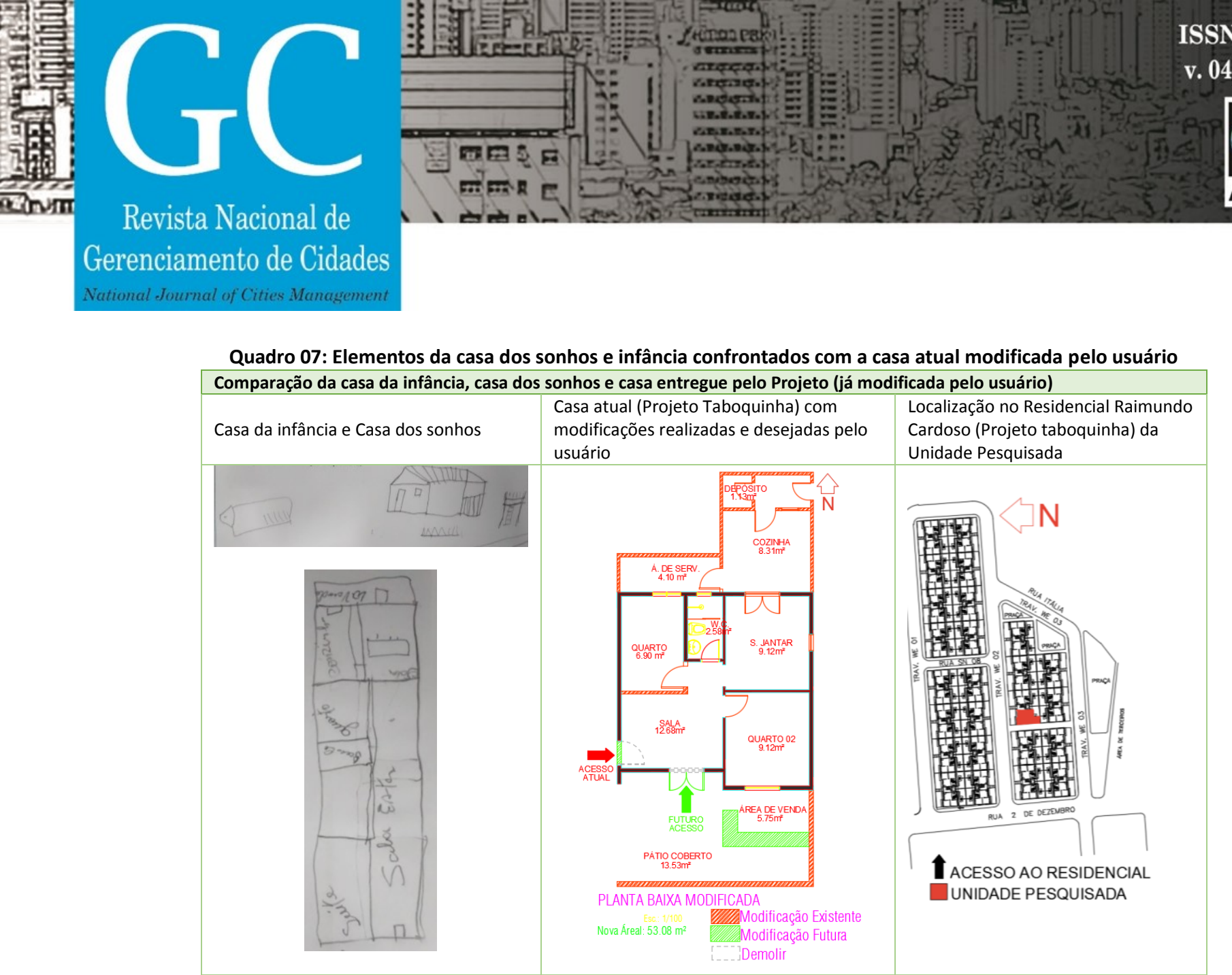

Fonte: PESQUISA DE CAMPO, 2014. Elaboração: ROSINEIDE TRINDADE.

É possível observar que a casa da infância era marcada pela presença da natureza, a própria fala da moradora demonstra esse vínculo: "Eu gosto de pendurar plantas, eu gosto de casa de pátio". A casa dos sonhos traz elementos significativos da cultura ribeirinha amazônica como a varanda, a disposição linear dos ambientes, a hierarquia entre os mesmos possibilitando privacidade. Aliás a privacidade representa uma das queixas dos moradores do sobrado, pois devido à configuração compacta e a ausência de circulação os cômodos ficam muito próximos e expostos; e também a conjugação da cozinha/sala é um fato destacado negativamente. Ao observar o sobrado modificado no mesmo quadro percebe-se a busca por esses elementos citados. Os moradores, de maneira informal alteram o sobrado resgatando os vínculos espaciais rompidos, ou seja, dentro das possibilidades de layout da unidade o morador busca adaptar os espaços e de forma natural e dentro do que é possível o que acontece é que a casa atual modificada vai se aproximando ou da casa da infância ou da casa dos sonhos, ou seja, das casas de referência do morador.

O Quadro 08 apresenta o desenho da unidade habitacional com as modificações realizadas e as desejadas pelo morador obtidas através de oficina em um dos residenciais do Projeto Taboquinha. O morador, com auxílio de um bolsista do projeto de pesquisa já mencionado, relata todas as modificações já realizadas na unidade habitacional e as que ainda serão feitas. 


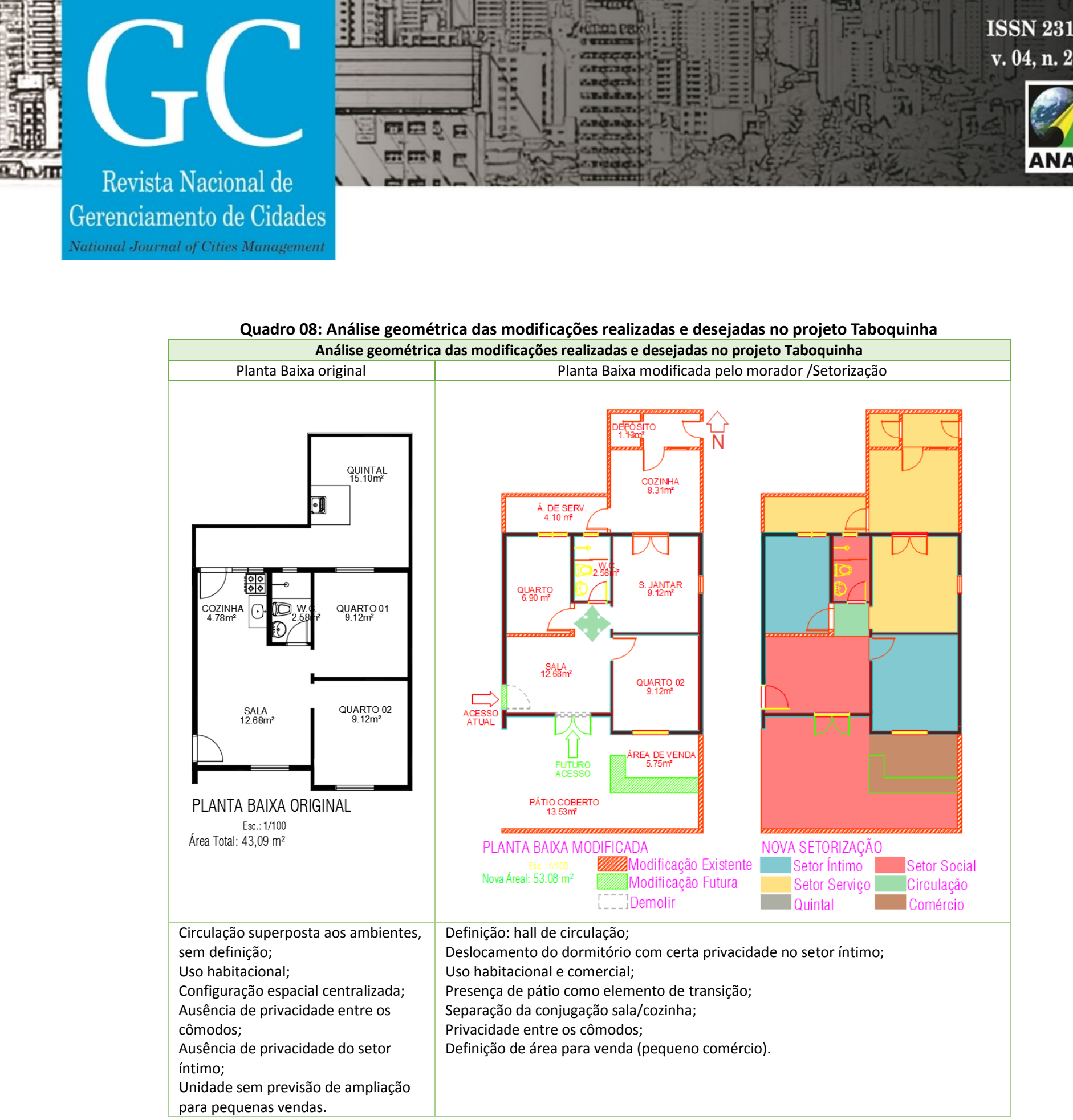
para pequenas vendas.

Fonte: PESQUISA DE CAMPO, 2014. Elaboração: ROSINEIDE TRINDADE.

Observa-se que o morador alterou a configuração inicial da unidade habitacional: criou-se uma circulação central definida, que dá acesso aos cômodos mais íntimos da casa, possibilitando mais privacidade aos ambientes e maior definição da setorização; a cozinha, como de costume, na casa anterior, volta a ocupar a parte posterior da habitação, sendo construída no lugar onde originalmente o projeto trazia o quintal; tomando a parte frontal do bloco, que pertence tanto ao apartamento do térreo quanto do primeiro pavimento, o morador construiu uma área coberta que funciona como um pátio, onde os vizinhos podem sentar para conversar ou simplesmente o morador pode observar e apreciar a movimentação na rua, situação comum nas áreas de palafitas, remetendo ao que Hertzberger (1996) fala sobre o "intervalo" que cumpre uma função social, pois permite a sociabilidade entre as pessoas, porém sem a invasão da privacidade da família, o "estar em casa e ao mesmo tempo fora de casa". Tal modificação 
evidenciou o espaço de transição também pensado como ambiente para as atividades de rendimento familiar. Nas modificações futuras será construída uma pequena área de venda de lanches, que já é realizada como meio de contribuição no orçamento familiar, porém sem um espaço apropriado.

As modificações realizadas e também as desejadas, apesar de possibilitarem algum tipo de adaptação, por serem feitas sem uma orientação técnica acabam trazendo perdas significativas, como por exemplo: a unidade habitacional com ampliação fica sem o espaço reservado para o quintal; a abertura de uma porta frontal oferece maior exposição do setor íntimo; há um comprometimento da janela do dormitório 01 por conta da ampliação no quintal e perda de áreas permeáveis.

Figura 04: Imagem das adaptações internas e externas nas unidades residenciais do Projeto Taboquinha
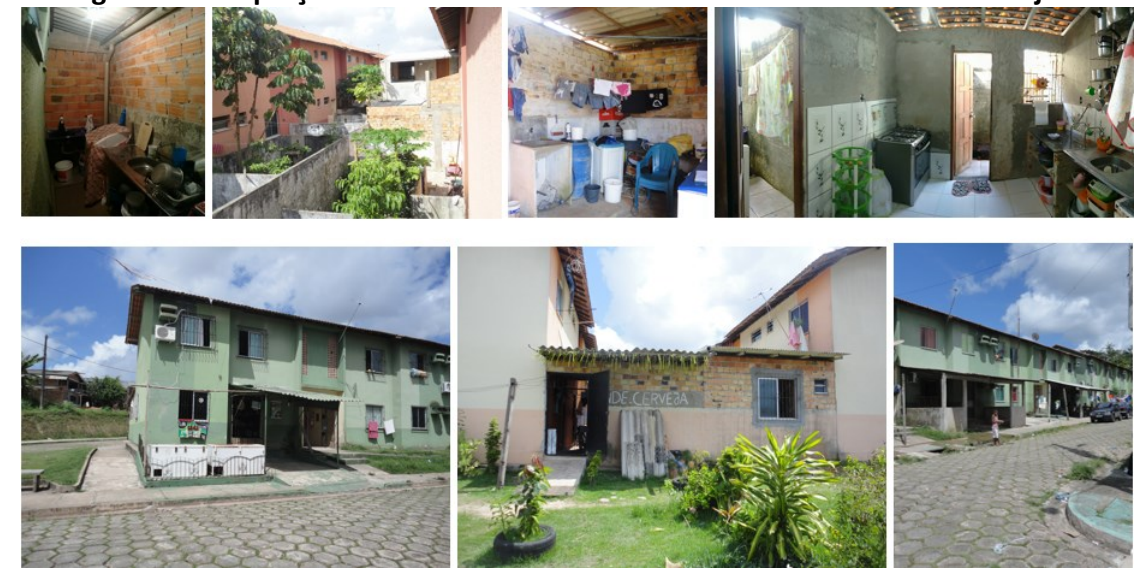

Fonte: LABORATÓRIO DE ESPAÇO E DESENVOLVIMENTO HUMANO (LEDH), 2015, 2014.

\section{CONCLUSÃO}

Os projetos de intervenções públicas na região amazônica tem demonstrado um direcionamento para suprir problemas principalmente relacionados ao espaço urbano.

Os resultados aqui apresentados demonstram que os aspectos atendidos por intervenções executadas pelo poder público, estão associados predominantemente a questões externas ao espaço habitacional, principalmente melhorias no sistema construtivo, no saneamento e infraestrutura.

O Projeto Taboquinha, a partir das respostas dos moradores, reforça as hipóteses iniciais de que a produção formal de habitação tem se mostrado uma das causas do rompimento de hábitos culturais e espaciais locais, evidenciados pelo confronto entre as condições da casa de origem e a casa destino, bem como, revela conflitos no espaço arquitetônico, o que ressalta a relevância do espaço para o ser humano, especialmente quando se trata da casa.

O trabalho também aponta que a adaptação habitacional tem sido a maneira recorrente para amenizar os conflitos espaciais, geralmente sem apoio técnico e proporcionais ao orçamento de cada família. $\mathrm{O}$ uso de espaços comuns aos moradores tem sido negociado entre as famílias 
reassentadas para promover a adaptação ao novo espaço habitacional. Com isso, conclui-se que os projetos de habitação social podem prever um maior comprometimento com a realidade local das famílias, com a formação do arquiteto mais envolvida com os condicionantes locais e a decorrente cultura espacial socialmente produzida para oferecer maior qualidade ao projeto de habitação social na Amazônia.

\section{AGRADECIMENTO}

Ao Edital MCTI/Cnpq/Mcidades no11/2012 pelo financiamento da pesquisa intitulada "O PAC Urbanização de Assentamentos Precários em Cidades Amazônicas: proposta metodológica para avaliação da produção e ocupação humana na política habitacional em Belém e Macapá".

\section{REFERÊNCIAS BIBLIOGRÁFICAS}

ABELÉM, A. G. Urbanização e remoção: por que e para quem?. (Centro de Filosofia e Ciências Humanas). Belém: NAEA/UFPA, 1989.

BONDUKI, Nabil. Política habitacional e inclusão social no Brasil: revisão histórica e novas perspectivas no governo Lula. Revista eletrônica de Arquitetura e Urbanismo, v. 1, p. 70-104, 2008.

BONDUKI, N. G.; ROSSETTO, R. Política e Sistema Nacional de Habitação de Interesse Social. In: AÇÕES INTEGRADAS DE URBANIZAÇÃO E ASSENTAMENTOS PRECÁRIOS. CURSO À DISTÂNCIA. MÓDULO I. Disciplina II. Brasília: Ministério das Cidades, 2008.

BRASIL. Programa de Aceleração do Crescimento 2007-2010. Brasília, 2007.

BRASIL. Ministério das Cidades. Secretaria Nacional de Habitação. Urbanização de Favelas: a experiência do PAC. Brasília, 2010.

COHAB-PA, COMPANHIA DE HABITAÇÃO DO PARÁ. Plano de Remanejamento Comunidade Taboquinha. Belém, 2011.

HERTZBERGER, H. Lições e Arquitetura; [tradução Carlos Eduardo Lima Machado]. São Paulo: Martins Fontes, 1996.

LOGSDON, L.; AFONSO, S.; OLIVEIRA, R. de. A funcionalidade e a flexibilidade como garantia de qualidade do projeto de habitação de interesse social. In: SIMPÓSIO BRASILEIRO DE QUALIDADE DO PROJETO NO AMBIENTE CONSTRUÍDO. Workshop Brasileiro de Gestão do Processo de Projeto na Construção de Edifícios, Rio de Janeiro, 2011. Anais...Rio de janeiro: UFRJ, 2011.

MALARD, M. L. As Aparências em Arquitetura. Belo Horizonte: Editora UFMG, 2006.

ROLNIK, Raquel. Democracia no fio da navalha: limites e possibilidades para a implementação de uma agenda de reforma urbana no Brasil. Revista Brasileira de Estudos Urbanos e Regionais, v. 11, n. 2, p. 31-50, 2011.

PERDIGÃO, A. K. de A. V. A dimensão afetiva da arquitetura de espaços habitacionais. São Paulo, SP: USP, 2005.

Originalmente apresentada como tese de doutorado, Universidade de São Paulo, 2005. 